\title{
A Case of Using Sports News in Teaching English to Sports Major Students in CDSI
}

\author{
Weiying Zhang ${ }^{1, a^{*}}$ \\ ${ }^{1}$ Chengdu Sport Institute, Chengdu, Sichuan, 610041, China \\ a zhangweiying@cdsu.edu.cn
}

Keywords: Sports news; Sports major students; English learning

\begin{abstract}
Over the past few decades, language teaching has been changed a lot, especially in foreign language teaching and learning. This paper aims to analyze the importance of using sports news in the classroom and tries to find ways on how to use sports news to teach English to sports major students. It is the results of in-depth study and also based on long term personal experience of teaching English to sports major students. Besides, activities and exercises are suggested which can be introduced into the classroom for an effective English language learning.
\end{abstract}

\section{Introduction}

With the coming of information era, medias has played an important role in daily life, especially in education. News, either print or digital, is regarded as a great source of language learning and it provides authentic materials for students of different majors. Swan (1985, p.85) indicates that "authentic material ... gives students a taste of 'real' language in use, and provides them with valid linguistic data for their unconscious acquisition processes to work on." And a classic example of authentic materials would be "a newspaper article that's written for a native-English-speaking audience (Sanderson,1999). Of all newspaper coverages, sports section has become one of the most popular sections among news readers(Roy Morgan, 2013).

In the era of globalization, any sport can attract players and audiences in any part of the globe. Sport is shaping and changing society and culture. Using sport as a context in language classrooms, combined with innovative pedagogy and cross curriculum approaches could engage students in their language learning.

\section{A Case of English Teaching in CDSI}

Chengdu Sport Institute (CDSI) is an institute who offers a variety of sports-related disciplines including Physical Education, Martial Arts and Athletic Sports etc.. To earn a bachelor degree, students are required to select enough courses with credits. In which, "College English" is a 4-semester compulsory course that every full-time students enrolled in CDSI has to take. However, these sports major students show the following problems in common:

Lower Entrance Score in English. The target students for CDSI are those who demonstrate sports potentialities. They spent a lot of time and efforts on training during high school which would interfere with their academic study. Gradually they lost their interests in learning at classrooms, especially to English, which requires a long time of memorizing and practicing. After entering the institute, they still put a lot of time on training rather than on English, resulting to their continuing lower English level.

Lack of Language. learning motivation and needs. For those who would like to learn English in the classroom, their goal is only to pass College English Test (CET-4) which is an English test that they must pass before graduation. These external or instrumental motivation would not lead to the sports major students' positivity in language learning, though passing the CET-4 is also helpful for their applying for a job in the near future.

No Language Learning Environment. The language learning environment is not suitable for students either in the classroom or after the class. An English class with 60 students registered is not 
suitable for language teaching. Students have less time to practice. Therefore, their English learning are mostly negative and passive. For their lack of motivation and confidence in language learning, students could not engaged into the class activities, which in turn contribute to their worse English speaking, listening, reading and writing.

\section{Authentic Materials in the Classroom}

Given the current situation, how to stimulate students' interests and their basic needs are very important. For their language learning, the obstacles they would encounter are new words, grammatical structure, useful expression and cultural background information. What if English teachers provide something that they are familiar with to facilitate their language learning? Widdowson (1990) believes that exposing language learners to authentic materials would make students feel that they are learning to communicate rather than language itself. Moreover, because of the rich language input they provide, students could be motivated by learning something designed for a native speaker and dealing with 'real' texts enables students to read more confidently and extensively outside the classroom.

Sports news on a learned newspaper would cover game reports, feature stories and personal columns about sports. With the information they are familiar with, students would feel more confident in reading, writing, listening and speaking. Moreover, students can get various benefits from sports news:

1. The most obvious one is increasing their vocabulary, especially the sports-related terms. Through the news reading, sports major students can accumulate English sports terms day by day within contexts, such as game report, feature stories of players and post views.

2. Through the authentic sports texts, students understand better about sports because the sports news is trending and relating a various practical aspects of the classroom subjects and their majors. Academic learning can be put into practice or viewed from a different view, which is helpful to their learning except for language.

3. Newspaper reading not only benefits students in their subjects but also improve the general knowledge and knowledge of culture. With the globalization, sports has become a useful tool to communicate with each other. Culture awareness and competence of Cross-cultural communication are improved through sports news reading.

4. Career pages, career point, jobs/career etc. are weekly published pages on a newspaper that helps students to learn and get knowledge about various jobs, exams and career-related issues.

\section{Challenges of Using Sports News}

Sports news are much more current than course books which are perfect for teachers to organize classroom activities and for sports major students to be confident and positive in language learning. But there are problems that they have to deal with in teaching and learning process.

1. Sports news selection is a time-consuming task.. Students' needs and interests are priority for teachers to consider. Moreover, difficulty and length should suit the students and class time. Besides, Teachers often spend a lot of time thinking up exercises to exploit news articles.

2. English teachers usually are lack of formal background in sport, who may feel shy from teaching sports terms with which students are more familiar with. Meanwhile, students are not familiar with the news structure. News tend to show a simple structure with short paragraphs and the first paragraph is the leading paragraph which states the most import information of a news.

3. News headlines would be hard for students to conquer, because they are cultural loaded and with some words omitted. Students need to be familiar with the commonly used words in sports headlines, such as edge meaning defeat. And they have to learn the omission rules used in headlines. For example: auxiliaries and coordinating conjunction are commonly omitted in a news headline.

4. Different sports events may have different terms to refer with, which could be found all of the texts. But because of the concise way newspaper texts are written, it can be particularly hard to follow 
the chain of reference. For example: in a game report of basketball, assist, rebound and banking shot prevail all the report.

\section{English Class Design}

According to Bloom's Taxonomy(1964), there are 6 levels that teacher can use to structure the learning objective which are: remembering, understanding, applying, analyzing, evaluating and creating. It is a framework to help teachers to design the class. When language teachers use authentic materials, sports news for example, the following figure 1 would fit the cognitive processes of the students, especially sports major students.

\section{Bloom's Taxonomy}

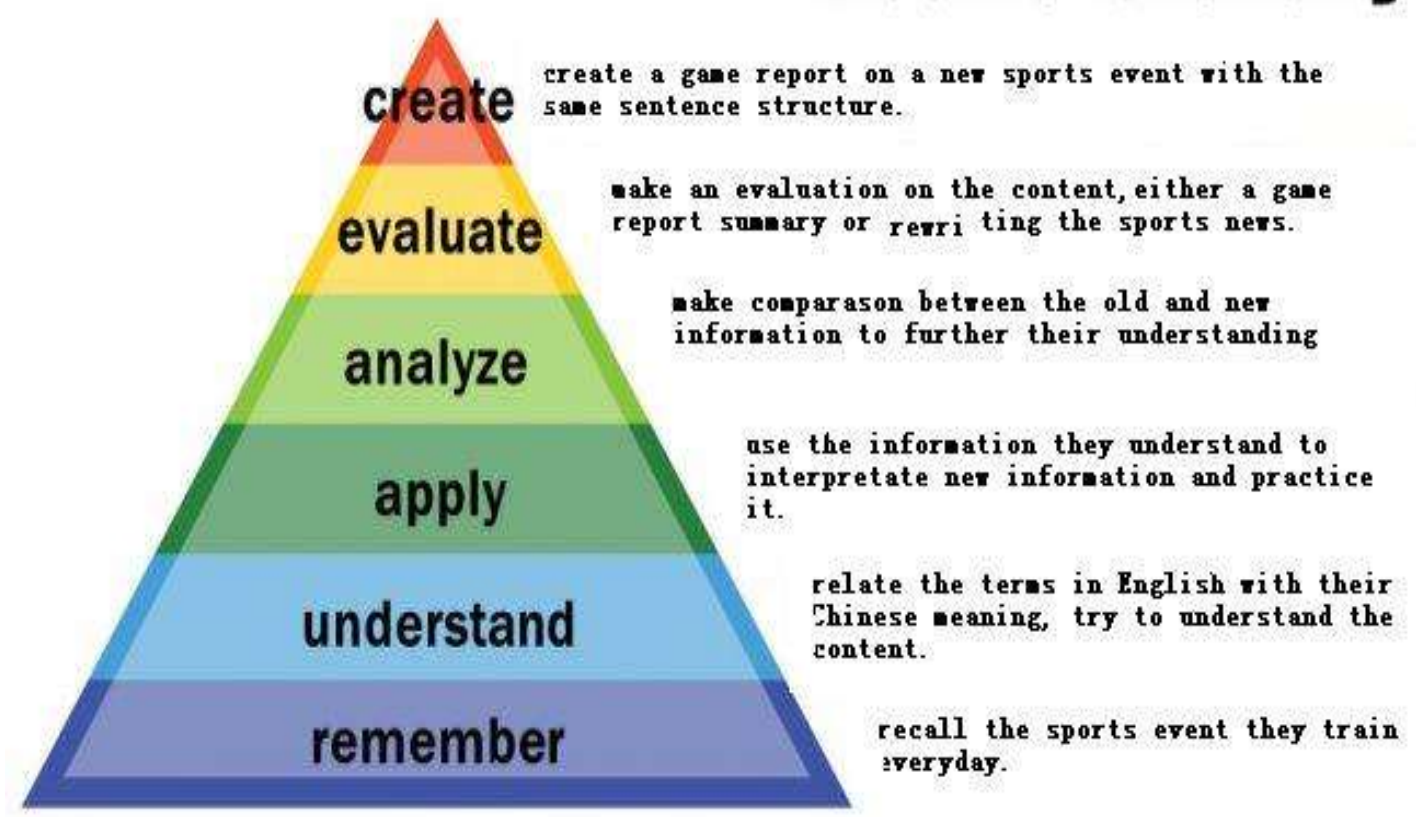

Figure 1 Bloom's Taxonomy

1. In the English classroom, the authentic sports news, either digital or in print, would arouse students' interests and gain their attention. SS would automatically recall the rules and technics that they train with everyday to make a relevance. Because they are familiar with the sports event, they feel ease to learn the language. Sports news lessens their anxiety in language learning and they would like move to the next cognitive level: understand.

2. SS autonomous learning would motivate their understanding and memorizing the sports terms in English. With the sufficient background information, SS would like to know the objective of today's class, and learning is enhanced when students are aware of the expectations for the English class(Marsh, 2007).

3. When SS gain enough confidence by reviewing the prior sports training knowledge, they would assess their own strengths and areas for continuing language learning. They are encouraged to use the information they know to interpret or crack down the new content, which is the sports news the teacher offers for the class.

4. The English teacher then design learning activities that involve SS to analyze, discuss, share, communicate with each other, so as to improve their understand and deepen their learning. The teacher could maximize SS learning by facilitating instructions.

5. The teacher would find out what the SS learns or if SS miss something via the next process--summary or rewriting. SS could also combine the old and new information and assess how much they would have learnt from the class, which might be very obvious. 
6. Homework could be the last process. SS are required to hand in another game reports to extend their understanding of the sports terms. At the same time the teacher could find anything missing in the language learning process and to improve the teacher's teaching.

\section{Summary}

Sports news could develop SS autonomy in language learning because sports major students have their specific features which might be different from other majors. Providing game reports in the classroom would lessen their anxiety and improve their confidence and motivation in language learning. Via sports news, teachers could design a series of activities for students to practice their 4 English language skills at the same time. The following is a whole English class pattern for English teachers to refer with.

1. provide a sports news, better covering a recent competition.

2. provide sports terms in advance for students to facilitate their reading.

3. watch a video clip and read the news on the same competition

4. ask SS to grasp the $5 \mathrm{Ws}$, notice the sentence structure and accumulate vocabulary

5. rewrite the sports news from a different perspective, either winning or defeating

6. ask SS to make a live report on the game

7. encourage SS to read outside class as much as possible.

These activities will help students improve their skills in language learning. In the language classroom, SS have to employ many critical thinking skills as they are required to interact with the authentic sports news. These autonomous learning would contribute to their language learning efficiency.

In conclusion, the sports news offers a special attraction for sports major students. It lessens the worries in the process of English learning for these lower students. It can also be used to enhance skills in reading, writing, listening, speaking because of the news's short sentence structure. Moreover, critical thinking is the natural outgrowth of using sports news to learn English. The sports news expands the curriculum with an unlimited amount of information to use as background for lanuage learning activities.

\section{Reference}

[1] B. Bloom, B. Mesia, D. Krathwohl: Taxonomy of Educational Objectives (two vols: The Affective Domain \& The Cognitive Domain). (New York. David McKay, 1964), 9. 122-136.

[2] H. W. Marsh: Students' evaluations of university teaching: Dimensionality, reliability, validity, potential biases, and usefulness. In R. Perry \& J. C. Smart (Eds.), The scholarship of teaching and learning in higher education: An evidence-based perspective, (Netherlands: Springer, 2007), p.319-383

[3] Roy Morgan(2013).The Top 10 most popular newspaper sections on Monday to Friday, Saturday and Sunday retrieved from: Information on http://www.roymorgan.com/findings/5102-newspaper-sectional-readership-preferences-weekda y-vs-weekend-march-2013-201308140032

[4] P. Sanderson: Using Newspapers in the Classroom. (Cambridge: Cambridge University Press, 1999), p. 19-32.

[5] M. Swan: A critical look at the communicative approach II. ELT Journal, Vol. 39(1985) No.1, p.76-87

[6] H.G. Widdowson: Aspects of Language Teaching, (Oxford, O.U.P, 1990), p.111-125.. 